\section{Hand injury prevention in India: Are we doing enough?}

Sir,

It was interesting to read the essay titled "Hand 2061," wherein the author deliberated upon the likely status of hand surgery in India in the year 2061. ${ }^{[1]}$ The author has lucidly taken us through the potential problems that India will face 50 years from now and has discussed the advances in the diagnosis, treatment and training of practitioners in a most convincing manner. ${ }^{[1]}$ However, we feel that of all these advances, what was not discussed and what is of utmost importance are the advances in hand injury prevention.

Advances in hand injury prevention, be it occupational hand injuries or injuries from road traffic accidents, must be the area of focus for the next 50 years. We must develop more effective, efficient and practical means to prevent hand injuries. Understanding the causation of Road Traffic Injuries (RTIs) and occupational hand injuries requires multidisciplinary inputs from traffic engineering, urban development, biomechanical engineers, police, public health specialists and epidemiologists, hand surgeons, psychologists, social scientists and others. In the absence of such multidisciplinary interaction in India, investigation and research of RTIs and elucidating causes have not received much importance. Besides that, under-reporting of RTIs is a serious and universal global problem, more so in India. ${ }^{[2]}$ Observations from pooled data of RTI study among 3077 patients from 23 hospitals in Bangalore by Gururaj et al. have shown that upper limbs are injured in $30.2 \%$ of the cases. ${ }^{[3]}$ Sathyasekaran noticed that head, thorax and abdomen, upper and lower extremities were damaged in $38 \%, 7 \%, 22 \%$ and $32 \%$, respectively, in a study of 1096 trauma patients. ${ }^{[4]}$ It is amply clear that hand and upper extremity injuries form a major chunk of RTIs. In India, as per our literature search, no systematic and scientific studies are available to highlight specific human, agent and environmental factors responsible for hand injuries. There is an urgent need for research into hand injury causation and prevention. Gururaj ${ }^{[5]}$ has made some recommendations regarding injury causation and prevention.

As hand surgeons and health care personnel, we can try to do the following:

- Integrate hand injury prevention into public health agenda and ongoing public health programmes.
- Develop epidemiology of hand injuries in our areas and have a detailed record of hand injuries to support further research.

- Augment trauma care skills at peripheral levels.

- Undertake lobbying and networking for road safety and occupational hand injury safety by providing leadership and coordination.

- Support and conduct research for developing and evaluating interventions.

- Try to translate research to policies.

We initiated a miniscule campaign on occupational hand injury prevention by distributing pamphlets on prevention of occupational hand injury in English and Marathi on World Labour Day 2011. In this, we explained common causes of occupational hand injuries, means of preventing them, first aid after injury and early care of the amputed part for the benefit of the workers.

Dedicated, unified and untiring efforts towards hand injury prevention will definitely yield positive outcomes in the times to come.

Nikhil Panse, Parag Sahasrabudhe Department of Plastic Surgery, B. J. Medical College and Sassoon Hospital, Pune, India

Address for Correspondence Dr. Nikhil Panse, Department of Plastic Surgery, Vimal Niwas, Sudarshan Society, Near Model Colony Post Office, Shivajinagar, Pune - 16, India. E-mail: nikhil.panse@rediffmail.com

\section{REFERENCES}

1. Freshwater MF. Hand 2061. Indian J Plast Surg 2011;44:368-70.

2. Mohan D. The road ahead: Traffic injuries and fatalities in India. Transportation Research and Injury Prevention Programme. Indian Institute of Technology, Delhi, 2004a.

3. Gururaj G, Reddi MN, Aeron Thomas A. Epidemiology of road traffic injuries in Bangalore. Proceedings of the 5th world conference on injury prevention and control. New Delhi: McMillan Publishers; 2000b.

4. Sathyasekaran BW. Study of the injured and the injury pattern in road traffic accident. Indian J Forensic Sci 1991;5:63-8.

5. Gururaj G. Road traffic injury prevention in India. National institute of mental health and neurosciences. Bangalore, India: Nimhans Publication number 56; 2006.

\begin{tabular}{|l|l|}
\multicolumn{3}{|c|}{ Access this article online } \\
\hline Quick Response Code: & Website: \\
\hline & www.ijps.org \\
\cline { 2 - 2 } & DOI: \\
\hline
\end{tabular}

